\title{
Accuracy and Inter observer variability of blood flow quantification on 4D flow MRI in adult with transposition of the great arteries corrected by arterial switch
}

\author{
Zahra Belhajer $^{1 *}$, Gilles Soulat ${ }^{2,1}$, Arshid Azarine ${ }^{2}$, Florence Pontnau ${ }^{2,1}$, Magalie Ladouceur ${ }^{2,1}$, Damien Bonnet ${ }^{3,1}$, \\ Laurence Iserin'2, Elie Mousseaux ${ }^{2,1}$
}

From 19th Annual SCMR Scientific Sessions

Los Angeles, CA, USA. 27-30 January 2016

\section{Background}

4D flow magnetic resonance imaging appears as a reliable tool for blood flow quantification. However, in patients with transposition of the great arteries corrected by arterial switch, the choice of a high velocity encoding (venc) to avoid velocity aliasing due to pulmonary stenosis, could decrease the accuracy of blood flow quantification in vessels such as superior or inferior vena cava (SVC, IVC) and atrio-ventricular valve (AVV) when blood velocities are lower.

Moreover, such accuracy of blood flow estimates can further be influenced by user experience in cardiac imaging due to manual intervention for $3 \mathrm{D}$ segmentation process of cardiac structures and correction of background phase offset.

Our aim was to investigate the accuracy and inter observer variability of quantitative MR 4D flow estimates in patients with transposition of the great arteries corrected by arterial switch (asTGA).

\section{Methods}

19 consecutives adults with asTGA underwent a nearly 10 minutes $4 \mathrm{D}$ flow MR acquisition (venc ranging from 300 to $400 \mathrm{~cm} / \mathrm{s}$, mean 350 in each direction). Two observers with level 1 and 3 in cardiac imaging performed manual correction of background phase offset and flow measurement in SVC, IVC, ascending and descending aorta (AA,DA); pulmonary trunk (PT), mitral and tricuspid valve (MV, TV). Conservation of flow

\footnotetext{
${ }^{1}$ Paris Descartes University, Paris, France

Full list of author information is available at the end of the article principle was used as an internal physiologic control for comparing blood flow estimates within great arteries (PT vs AA), AVV (TV vs MV), and comparing arterial and venous blood flow of upper body ( AA-DA vs SVC) and lower body ( IVC vs DA) circulations.

\section{Results}

Arterial and venous blood flow measurement $(1 / \mathrm{min})$ were better correlated for great arteries (GA) $(r=0,92)$ or atrioventricular valves $(\mathrm{AVV})(\mathrm{r}=0,91)$ than the upper $(r=0,74)$ and lower body circulation $(r=0,75)$. All these correlations were better when blood flow estimates of the level 3 observer were taken into account compared to level 1 observer estimates: GA ( $r=0.92$; $\mathrm{p}<0.0001$ vs $\mathrm{r}=0.78 ; \mathrm{p}<0.0001), \operatorname{AVV}(\mathrm{r}=0.91 \mathrm{p}<$ 0.0001 vs $\mathrm{r}=0.69 ; \mathrm{p}=0.008)$, upper body $(\mathrm{r}=0.74 ; \mathrm{p}=$ 0.0004 ; NS) and lower body $(r=0.75 \mathrm{p}=0.0002$ vs $\mathrm{r}=$ $0.49 ; \mathrm{p}=0.03)$. Bland and Altman analysis further showed smaller mean differences between GA, AVV, upper and lower body when using level 3 observer estimates $(0.01 ; 0.15 ; 0.25 ; 0 ; 14 \mathrm{l} / \mathrm{min}$ respectively) than when using level 1 observer estimates $(0.16 ; 0.19 ; 0.27$; $0.53 \mathrm{l} / \mathrm{min}$ respectively).

When blood flow estimates of the two observers are directly compared, coefficient of variation were $8.7 \%$ and $8.1 \%$ in $\mathrm{AA}$ and $\mathrm{PT}, 12.5 \%$ in DA, $13.5 \%$ and $25 \%$ in $\mathrm{TV}$ and MV, $17.9 \%$ and $23.0 \%$ in SVC and IVC.

\section{Conclusions}

Taking into account the conservation of flow as an internal validation, accurate blow flow estimates, have been obtained in GA and AV valve of patients with 
asTGA after using a $350 \mathrm{~cm} / \mathrm{sec}$ of encoding flow velocity due to pulmonary stenosis. Reliability of 4D flow measurement in venous circulation seems to be lower due to much lower velocities. Furthermore, this accuracy is influenced by observer experience.

\section{Authors' details}

'Paris Descartes University, Paris, France. ${ }^{2}$ European Hospital Georges

Pompidou, Paris, France. ${ }^{3}$ Necker hospital for sick children, Paris, France.

Published: 27 January 2016

doi:10.1186/1532-429X-18-S1-P153

Cite this article as: Belhajer et al: Accuracy and Inter observer variability of blood flow quantification on 4D flow MRI in adult with transposition of the great arteries corrected by arterial switch. Journal of

Cardiovascular Magnetic Resonance 2016 18(Suppl 1):P153.

Submit your next manuscript to BioMed Central and take full advantage of:

- Convenient online submission

- Thorough peer review

- No space constraints or color figure charges

- Immediate publication on acceptance

- Inclusion in PubMed, CAS, Scopus and Google Scholar

- Research which is freely available for redistribution

Submit your manuscript at www.biomedcentral.com/submit 